\title{
Epidemiology of influenza in pregnant women hospitalized with respiratory illness in Moscow, 2012/2013-2015/2016: a hospital-based active surveillance study
}

Svetlana Trushakova" ${ }^{*}$, Lidiya Kisteneva', Beatriz Guglieri-López², Evgenia Mukasheva', Irina Kruzhkova', Ainara Mira-Iglesias², Kirill Krasnoslobodtsev², Ekaterina Morozova², Ludmila Kolobukhina', Joan Puig-Barberà2† and Elena Burtseva ${ }^{1+}$

\begin{abstract}
Background: To better understand the impact of seasonal influenza in pregnant women we analyzed data collected during four seasons at a hospital for acute respiratory infection that specializes in treating pregnant women.

Methods: This was a single-center active surveillance study of women 15-44 years of age hospitalized for acute respiratory diseases between 2012/2013 and 2015/2016 in Moscow, Russian Federation. Women had to have been hospitalized within 7 days of the onset of symptoms. Swabs were taken within $48 \mathrm{~h}$ of admission, and influenza was detected by reverse transcription-polymerase chain reaction.

Results: During the four seasons, of the 1992 hospitalized women 1748 were pregnant. Laboratory-confirmed influenza was detected more frequently in pregnant women (825/1748; 47.2\%) than non-pregnant women (58/244; $23.8 \%$ ) (OR for influenza $=2.87$ [95\% Cl, 2.10-3.92]; $p<0.001)$. This pattern was homogenous across seasons $(p=0.112$ by test of homogeneity of equal odds). Influenza A(H1N1)pdm09 was the dominant strain in 2012/2013, A(H3N2) in 2013/2014, B/ Yamagata lineage and $A(H 3 N 2)$ in 2014/2015, and A(H1N1)pdm09 in 2015/2016. Influenza-positive pregnant admissions went to the hospital sooner than influenza-negative pregnant admissions $(p<0.001)$. The risk of influenza increased by $2 \%$ with each year of age and was higher in women with underlying conditions ( $\mathrm{OR}=1.52[95 \% \mathrm{Cl}, 1.16$ to 1.99$]$ ). Pregnant women positive for influenza were homogeneously distributed by trimester ( $p=0.37$ for homogeneity; $p=0.49$ for trend). Frequencies of stillbirth, delivery, preterm delivery, and caesarean delivery did not significantly differ between influenza-positive and influenza-negative hospitalized pregnant women or between subtypes/lineages.
\end{abstract}

Conclusions: Pregnant women are at increased risk for hospitalization due to influenza irrespective of season, circulating viruses, or trimester.

Keywords: Influenza, Pregnancy, Hospitalization, Surveillance

\footnotetext{
* Correspondence: s.trushakova@gmail.com

†Joan Puig-Barberà and Elena Burtseva contributed equally to this work.

"Ministry of Health of the Russian Federation, FSBI "N.F. Gamaleya NRCEM",

16, Gamaleya str, Moscow, Russia Moscow 123098, Russian Federation

Full list of author information is available at the end of the article
}

(c) The Author(s). 2019 Open Access This article is distributed under the terms of the Creative Commons Attribution 4.0 International License (http://creativecommons.org/licenses/by/4.0/), which permits unrestricted use, distribution, and reproduction in any medium, provided you give appropriate credit to the original author(s) and the source, provide a link to the Creative Commons license, and indicate if changes were made. The Creative Commons Public Domain Dedication waiver (http://creativecommons.org/publicdomain/zero/1.0/) applies to the data made available in this article, unless otherwise stated. 


\section{Background}

Pregnant women are at increased risk of severe influenza illness and influenza-related death [1-3] and, during all trimesters, are at increased risk of hospital admission due to influenza infection [4]. Influenza illness during pregnancy also appears to be associated with increased rates of stillbirth, neonatal death, preterm delivery, and low birth weight [5-7]. In 2012, the World Health Organization expanded its recommendations for seasonal influenza vaccination to all pregnant women [8]. Maternal influenza vaccination does not pose a risk to the developing fetus [9] and may reduce stillbirth, growth restriction, and preterm birth [10-12].

Due to small study populations and designs that limit interpretation, the real impact of influenza on pregnant women remains uncertain $[4,13,14]$. Also, many of the severe cases of influenza analyzed occurred during the 2009 A(H1N1)pdm09 pandemic, when women may have been hospitalized for precautionary reasons [4]. Additional data are therefore needed to evaluate and support vaccination policies for pregnant women.

The present investigation was conducted as part of the Global Influenza Hospital Surveillance Network (GIHSN) that aims to generate data on the impact of influenza virus infection during hospitalization. The GIHSN is an international collaboration launched in 2012 to improve understanding of influenza epidemiology and better inform public health policy decisions [15]. The GIHSN has run a multinational, prospective, hospital-based active surveillance study to collect epidemiological data over several consecutive years. Sites included in the GIHSN use a standardized protocol and standard operating procedures, allowing results to be compared and pooled [16].

Since 2012, the Federal Budget Institute of Health "Clinical Hospital for Infectious Diseases No. 1" (CHID\#1) in Moscow, Russian Federation has participated in the GIHSN. CHID\#1 is one of two reference hospitals for acute respiratory diseases in Moscow and specializes in treating pregnant women. Here, we analyzed data collected from CHID\#1 during the four seasons since its inclusion in the GIHSN (2012/2013 to 2015/2016) to describe the epidemiology of influenza in hospitalized pregnant women, and evaluate the clinical symptoms and outcomes of influenza-associated acute respiratory illness in this population.

\section{Methods}

\section{Study design}

This was a prospective, active surveillance hospital-based study conducted during the 2012/2013 to 2015/2016 influenza seasons at CHID\#1 (Moscow, Russian Federation). CHID\#1 is a unique, specialized department hospital for pregnant women with infectious diseases. The study was performed due to the study site's participation in the
GIHSN international influenza surveillance project and its use of the standardized GIHSN protocols [16].

\section{Study conduct}

Patients admitted to the participating hospital were included, after written consent, if they were residents in the predefined hospital's catchment area, presented with an acute illness possibly related to influenza, were not institutionalized, and were admitted within 7 days of the onset of symptoms. Patients discharged during the previous 30 days were excluded. Swabs were collected within $48 \mathrm{~h}$ from patients meeting the inclusion criteria and tested by reverse transcription-polymerase chain reaction (RT-PCR) for influenza. Influenza-positive samples were sub-typed by RT-PCR to identify $\mathrm{A}(\mathrm{H} 1 \mathrm{~N} 1) \mathrm{pdm} 09, \mathrm{~A}(\mathrm{H} 3 \mathrm{~N} 2), \mathrm{B} /$ Yamagata-lineage, and B/Victoria-lineage strains.

The present analysis was limited to women $15-44$ years of age admitted with an acute respiratory infection, in line with the age range used by others $[3,17,18]$. All other aspects of patient selection were in accordance with the GIHSN study protocol [16]. RT-PCR was conducted at the World Health Organization National Influenza Centre at the Ivanovsky Institute of Virology (Moscow, Russian Federation) using Amplisens ${ }^{\circ}$ Ribo-sorb and Ribo-prep (Federal Budget Institute of Science "Central Research Institute for Epidemiology", Moscow, Russian Federation) or a PREP-NA DNA/RNA extraction kit (DNA-Technology, Moscow, Russian Federation) to extract RNA; a Reverta-L kit (Federal Budget Institute of Science "Central Research Institute for Epidemiology") for reverse transcription; and kits from Federal Budget Institute of Science "Central Research Institute for Epidemiology" and DNA-Technology to amplify influenza A, A(H1N1), A(H3N2), A(H1N1)pdm09, and $\mathrm{B}$ genes.

Socio-demographic and clinical information were collected by face-to-face interviews with patients or attending physicians or by reviewing clinical records. Information collected included socio-demographic characteristics, the major complaint at admission, smoking habits, underlying conditions, vaccination status, pregnancy outcome during the current admission, clinical course, and major diagnosis at discharge. Registered pregnancy outcomes included abortion (terminated at $<20$ weeks gestational age), stillbirth ( $\geq 20$ weeks gestational age with no heartbeat or respiratory effort), delivery (birth at any gestational age with heartbeat or respiratory effort), live preterm birth $(<37$ weeks of gestation), low birth weight $(<2500 \mathrm{~g})$, perinatal death (i.e. during the mother's current admission), and caesarean delivery. Main discharge diagnoses were recorded by the physician using ICD-10 codes.

\section{Statistical analysis}

Statistical analyses were restricted to women recruited in periods with continuous influenza circulation, defined as 
$\geq 2$ admissions positive for influenza in $\geq 2$ consecutive weeks. Calendar time (admission week) was modeled using restricted cubic splines with four knots. The number of knots was set based on the Akaike information criterion [19]. The odds ratio (OR) of admission with influenza was calculated by bivariate logistic regression using the category with the lowest value as the reference. To estimate the significance of differences among groups, chi-squared, likelihood ratio, $t$, and nonparametric K-sample tests were used. For comparisons of continuous variables among multiple categories, equality of medians and one-way analysis of variance were used with Scheffe correction for multiple comparisons. Likelihood ratio tests were used to check for confounding, interaction, linearity, and clustering. The adjusted odds ratio (aOR) of influenza among pregnant women was estimated by multivariate logistic regression using minimal sufficient adjustment by variables identified as confounders by causal diagrams (e.g. age, underlying conditions, smoking habits, admissions in the previous year, time to swab, season, and epidemiological week at admission). The goodness of fit of the models was assessed using Akaike and Bayesian information criteria. Conditional plots [20] of the average predicted probability of influenza positive admission and of pregnancy outcome during admission were used to assess complex relationships between the pregnant women's age in years, their infant's gestational age, underlying conditions, influenza infection, and infection by A subtype or B lineage. The predicted probabilities of either influenza infection or pregnancy outcomes during admission were adjusted by age, smoking habits, chronic underlying conditions, admission in previous 12 months, pregnancy trimester, time to swab, and calendar time (season-week) as restricted cubic splines. All $p$-values were two-tailed. A $p$-value $<0.05$ was considered to indicate statistical significance. Heterogeneity in the effects of risk factors were quantified using the $\mathrm{I}^{2}$ test, with heterogeneity defined as an $\mathrm{I}^{2}>50 \%$. All statistical analyses were performed with Stata/SE version 14 (College Station, TX, USA).

\section{Results}

\section{Included population}

The study included 1992 women 15-44 years old admitted for acute respiratory diseases between 2012/2013 and 2015/ 2016. Of these admissions, 1748 were pregnant (Table 1). Influenza was detected in $47.2 \%(825 / 1748)$ of pregnant admissions and 23.8\% (58/244) of non-pregnant admissions (OR for influenza $=2.87$ [95\% confidence interval (CI), 2.10-3.92]; $p<0.001$; data not shown). Proportions of pregnant admissions with influenza were similar during the four influenza seasons included $(48.7 \%$ in $2012 / 2013,44.5 \%$ in $2013 / 2014$, $52.4 \%$ in $2014 / 2015$, and $44.9 \%$ in $2015 / 2016$; $p=0.112$ by test for homogeneity of equal odds; data not shown). Proportions of non-pregnant women with influenza were not analyzed further because of insufficient numbers. The main comparative assessment and conclusions were made by comparing hospitalized influenza-positive pregnant women with hospitalized influenza-negative pregnant women.

\section{Influenza circulation}

During the four influenza seasons included in this study, influenza was detected during similar periods, although the season varied from as short as 13 weeks in 2014/2015 to as long as 24 weeks in 2015/2016, and the peak occurred as early as week 3 in 2015/2016 and as late as week 11 in 2013/2014 (Fig. 1). Influenza A(H1N1)pdm09 was the dominant strain in 2012/2013, A(H3N2) in 2013/2014, B/ Yamagata lineage and $\mathrm{A}(\mathrm{H} 3 \mathrm{~N} 2)$ in $2014 / 2015$, and A(H1N1)pdm09 in 2015/2016 (Table 1 and Fig. 1).

Table 1 Influenza infection status in pregnant admissions

\begin{tabular}{|c|c|c|c|c|c|}
\hline \multirow[b]{3}{*}{ RT-PCR result } & \multicolumn{5}{|l|}{ n (\%) } \\
\hline & $2012 / 2013$ & 2013/2014 & $2014 / 2015$ & $2015 / 2016$ & All seasons \\
\hline & $N=520$ & $N=335$ & $N=296$ & $N=597$ & $N=1748$ \\
\hline \multicolumn{6}{|l|}{ RT-PCR result } \\
\hline Positive $^{a}$ & $253(48.7)$ & $149(44.5)$ & $155(52.4)$ & $268(44.9)$ & $825(47.2)$ \\
\hline Negative & $267(51.3)$ & $186(55.5)$ & $141(47.6)$ & $329(55.1)$ & $923(52.8)$ \\
\hline \multicolumn{6}{|l|}{ Influenza type } \\
\hline A(H1N1)pdm09 & $155(61.3)$ & $13(8.7)$ & $11(7.1)$ & $182(67.9)$ & 361 (43.8) \\
\hline $\mathrm{A}(\mathrm{H} 3 \mathrm{~N} 2)$ & $41(16.2)$ & $100(67.1)$ & $62(40.0)$ & $21(7.8)$ & $224(27.2)$ \\
\hline B/Yamagata lineage & $6(2.4)$ & $34(22.8)$ & $66(42.6)$ & $0(0.0)$ & $106(12.8)$ \\
\hline B/Nictoria lineage & $10(4.0)$ & $2(1.3)$ & $5(3.2)$ & $59(22.0)$ & $76(9.2)$ \\
\hline A not subtyped & $5(2.0)$ & $0(0.0)$ & $1(0.6)$ & $2(0.7)$ & $8(1.0)$ \\
\hline B undetermined lineage & $36(14.2)$ & $0(0.0)$ & $10(6.5)$ & $4(1.5)$ & $50(6.1)$ \\
\hline
\end{tabular}

Abbreviation: $R T-P C R$ reverse transcription-polymerase chain reaction

${ }^{\mathrm{a}}$ Test of homogeneity (equal odds) between seasons: $p=0.1176$ 


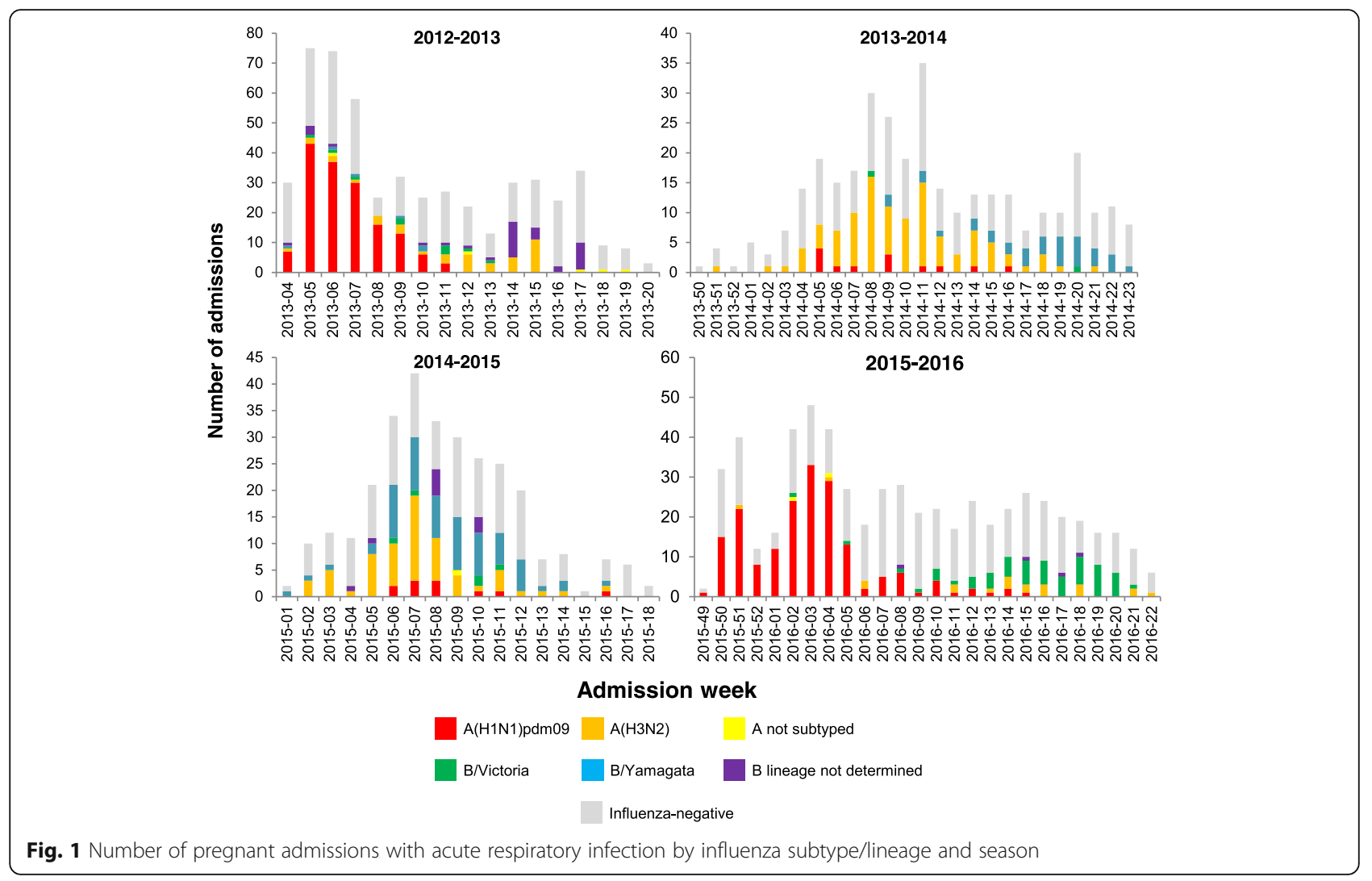

\section{Characteristics of influenza-positive pregnant admissions} Influenza-positive pregnant admissions were slightly older than influenza-negative pregnant admissions ( median $=28.5$ vs. 28.0 years; $\mathrm{OR}=1.02$ [95\% CI, $1.00-1.04] ; p=0.021$ ) (Table 2). The risk of a positive influenza result increased with each year by $2 \%$ ( $95 \% \mathrm{CI}, 0-4 \%)$. When analyzed by subtype/lineage, the probability of influenza infection increased with each additional year by $3 \%(95 \%$ CI, $1-6 \%$; $p=$ $0.012)$ for $\mathrm{A}(\mathrm{H} 1 \mathrm{~N} 1) \mathrm{pdm} 09$ and by $9 \%(4-13 \% ; p<0.001)$ for $B$ /Yamagata lineage but was unaffected by age for $\mathrm{A}(\mathrm{H} 3 \mathrm{~N} 2)$ and $\mathrm{B} /$ Victoria lineage (Table 4). Median ages were higher for pregnant admissions positive for $\mathrm{B}$ /Yamagata-lineage viruses (30 years) than for those positive for $\mathrm{A}(\mathrm{H} 1 \mathrm{~N} 1) \mathrm{pdm} 09$ (29 years; $p=0.01), \mathrm{A}(\mathrm{H} 3 \mathrm{~N} 2)$ (28 years; $p=$ 0.006 ), or $\mathrm{B} /$ Victoria lineage (28 years; $p=0.006$ ) (Table 3 ). Minor but significant differences in age were found for pregnant admissions by influenza subtype/lineage $(p=0.028)$.

Pregnant admissions who were positive for influenza more frequently had underlying conditions than those who were negative for influenza $(\mathrm{OR}=1.52[95 \% \mathrm{CI}$, $1.16-1.99], p=0.003 ; \mathrm{aOR}=1.56$ [95\% CI, 1.16-2.08]) (Tables 2 and 4). This was confirmed for influenza $\mathrm{A}(\mathrm{H} 3 \mathrm{~N} 2)$ and $\mathrm{A}(\mathrm{H} 1 \mathrm{~N} 1)$ but not for the two $\mathrm{B}$ lineages (Table 4). However, significant differences between influenza-positive and influenza-negative pregnant admissions were not detected for the individual underlying conditions (Tables 2 and 3 ).
Gestational age distribution was similar in influenza-positive and influenza-negative pregnant admissions $(p=0.872)$ (Table 2). Pregnant admissions positive for influenza were homogeneously distributed by trimester $(p=0.37$ for homogeneity in the distribution of estimates and $p=0.49$ for trend, data not shown). The OR of admission with any influenza did not differ between the first and second trimesters (1.19 [95\% CI, 0.92-1.53]; $p=0.16$ ) or between the first and third trimesters $(1.12$ [95\% CI, $0.86-1.46] ; p=0.39$ ). Most of the pregnant admissions infected with influenza $\mathrm{A}(\mathrm{H} 1 \mathrm{~N} 1) \mathrm{pdm} 09$ or B/Victoria lineage were in the first or second trimester, whereas most of those infected with influenza $\mathrm{A}(\mathrm{H} 3 \mathrm{~N} 2)$ or B/Yamagata lineage were in the second or third trimester, resulting in a significant difference in strain distribution by trimester $(p=0.005)$ (Table 3); however, aORs for each strain did not differ between trimesters (Table 4). Likewise, distributions of gestational age at admission differed significantly by virus subtype/lineage, and median gestational ages were lower for admissions positive for $\mathrm{A}(\mathrm{H} 1 \mathrm{~N} 1) \mathrm{pdm} 09$ (21 weeks) than for admissions positive for $\mathrm{A}(\mathrm{H} 3 \mathrm{~N} 2)$ (25 weeks; $p=0.032$ [data not shown]) or $\mathrm{B} /$ Yamagata lineage (24 weeks; $p=0.027$ [data not shown]) (Table 3). Conditional plots did not reveal interactions between trimester and patient age or presence of underlying conditions for the risk of admission with any influenza or with each subtype/lineage (Additional file 1). 
Table $\mathbf{2}$ Characteristics of pregnant admissions by influenza infection status

\begin{tabular}{|c|c|c|c|c|}
\hline \multirow[t]{2}{*}{ Characteristic } & \multirow{2}{*}{$\begin{array}{l}\text { Influenza positive } \\
N=825\end{array}$} & \multirow{2}{*}{$\begin{array}{l}\text { Influenza negative } \\
\mathrm{N}=923\end{array}$} & \multirow[t]{2}{*}{ OR $(95 \% \mathrm{Cl})$} & \multirow[t]{2}{*}{$P$-value } \\
\hline & & & & \\
\hline \multicolumn{5}{|l|}{ Age group, n (\%) } \\
\hline $15-19$ years & $27(3.3)$ & $42(4.6)$ & 1 & \\
\hline 20-24 years & $153(18.6)$ & $214(23.2)$ & $1.11(0.66-1.88)$ & 0.692 \\
\hline $25-29$ years & $327(39.6)$ & $341(36.9)$ & $1.49(0.90-2.48)$ & 0.122 \\
\hline $30-34$ years & $206(25.0)$ & $214(23.2)$ & $1.50(0.89-2.52)$ & 0.128 \\
\hline $35-39$ years & 89 (10.8) & $94(10.2)$ & $1.47(0.84-2.59)$ & 0.178 \\
\hline 40-44 years & $23(2.8)$ & $18(2.0)$ & $1.99(0.91-4.35)$ & 0.086 \\
\hline Median age in years (range) & $28.5(15-44)$ & $28(15-44)$ & $1.02(1.00-1.04)$ & 0.021 \\
\hline \multicolumn{5}{|l|}{ Underlying conditions, n (\%) } \\
\hline One or more & $136(16.5)$ & $106(11.5)$ & $1.52(1.16-1.99)$ & 0.003 \\
\hline Cardiovascular disease & $28(3.4)$ & $23(2.5)$ & $1.37(0.78-2.40)$ & 0.268 \\
\hline Chronic obstructive pulmonary disease & $12(1.5)$ & $8(0.9)$ & $1.68(0.69-4.14)$ & 0.256 \\
\hline Asthma & $10(1.2)$ & $6(0.7)$ & $1.87(0.68-5.17)$ & 0.227 \\
\hline Diabetes $^{\text {a }}$ & $0(0.0)$ & $3(0.3)$ & $0.29(0.00-2.71)$ & 0.294 \\
\hline Renal impairment & $68(8.2)$ & $54(5.9)$ & $1.44(0.99-2.09)$ & 0.053 \\
\hline Cirrhosis & $9(1.1)$ & $8(0.9)$ & $1.26(0.48-3.28)$ & 0.637 \\
\hline Neuromuscular ${ }^{a}$ & $1(0.1)$ & $0(0.0)$ & $1.12(0.03-\infty)$ & 0.944 \\
\hline Neoplasm & $2(0.2)$ & $2(0.2)$ & $1.12(0.16-7.95)$ & 0.912 \\
\hline Rheumatic disease ${ }^{a}$ & $0(0.0)$ & $1(0.1)$ & $1.12(0.00-43.63)$ & 1.000 \\
\hline Antiviral treatment before admission, $\mathrm{n}(\%)$ & $8(1.0)$ & $11(1.2)$ & $0.81(0.32-2.02)$ & 0.652 \\
\hline Influenza vaccination, n (\%) & $3(0.4)$ & $3(0.3)$ & $0.99(0.97-1.01)$ & 0.392 \\
\hline \multicolumn{5}{|l|}{ Trimester of pregnancy, n (\%) } \\
\hline First (0-13 weeks) & $177(21.5)$ & $221(23.9)$ & 1 & \\
\hline Second (14-26 weeks) & $355(43.0)$ & $372(40.3)$ & $1.19(0.93-1.52)$ & 0.162 \\
\hline Third (27-42 weeks) & $291(35.3)$ & $325(35.2)$ & $1.12(0.87-1.44)$ & 0.388 \\
\hline Gestational age at admission (weeks), median (range) & $23(1-41)^{b}$ & $23(3-42)^{c}$ & $1.00(0.99-1.01)$ & 0.872 \\
\hline \multicolumn{5}{|l|}{ Smoking habits, n (\%) } \\
\hline Never smoked & $563(68.2)$ & $602(65.2)$ & 1 & \\
\hline Past smoker & $225(27.3)$ & $268(29.0)$ & $0.90(0.73-1.11)$ & 0.317 \\
\hline Current smoker & $37(4.5)$ & $53(5.7)$ & $0.75(0.48-1.15)$ & 0.188 \\
\hline \multicolumn{5}{|l|}{ Socioeconomic class, n (\%) } \\
\hline Managerial & $359(43.5)$ & $383(41.5)$ & 1 & \\
\hline Skilled & $360(43.6)$ & $425(46.0)$ & $0.9(0.74-1.10)$ & 0.324 \\
\hline Unskilled & $34(4.1)$ & $52(5.6)$ & $0.7(0.44-1.10)$ & 0.121 \\
\hline Other & $72(8.7)$ & $63(6.8)$ & $1.22(0.84-1.76)$ & 0.29 \\
\hline \multicolumn{5}{|l|}{ Time from onset of symptoms to swabbing, n (\%) } \\
\hline $0-2$ days & $559(67.8)$ & $541(58.6)$ & 1 & \\
\hline $3-4$ days & $228(27.6)$ & $280(30.3)$ & $0.79(0.64-0.97)$ & 0.027 \\
\hline $5-7$ days & $38(4.6)$ & $102(11.1)$ & $0.36(0.24-0.53)$ & 0.001 \\
\hline Days from onset of symptoms to swabbing, median (range) & $2(0-7)$ & $2(0-7)$ & $0.87(0.82-0.93)$ & 0.001 \\
\hline
\end{tabular}


Table 3 Characteristics of pregnant admissions by influenza subtype/lineage

\begin{tabular}{|c|c|c|c|c|c|}
\hline \multirow[t]{2}{*}{ Characteristic } & A(H1N1)pdm09 & $\mathrm{A}(\mathrm{H} 3 \mathrm{~N} 2)$ & B/Yamagata & B/Victoria & \multirow[t]{2}{*}{$P$-value } \\
\hline & $N=361$ & $N=224$ & $N=106$ & $N=76$ & \\
\hline Age group, n (\%) & & & & & 0.028 \\
\hline $15-19$ years & $11(3.0)$ & $10(4.5)$ & $2(1.9)$ & $2(2.6)$ & \\
\hline $20-24$ years & $69(19.1)$ & $40(17.9)$ & $17(16.0)$ & $19(25.0)$ & \\
\hline $25-29$ years & $146(40.4)$ & $95(42.4)$ & $31(29.2)$ & $30(39.5)$ & \\
\hline 30-34 years & $91(25.2)$ & $51(22.8)$ & $31(29.2)$ & $23(30.3)$ & \\
\hline $35-39$ years & $37(10.2)$ & $21(9.4)$ & $18(17.0)$ & $1(1.3)$ & \\
\hline 40-44 years & $7(1.9)$ & $7(3.1)$ & $7(6.6)$ & $1(1.3)$ & \\
\hline Age (years), median (range) & $29(17-44)$ & $28(15-43)$ & $30(19-42)$ & $28(19-45)$ & 0.004 \\
\hline \multicolumn{6}{|l|}{ Underlying conditions ${ }^{\mathrm{a}}, \mathrm{n}(\%)$} \\
\hline None & $300(83.1)$ & $182(81.3)$ & $92(86.8)$ & $63(82.9)$ & 0.666 \\
\hline One or more & $61(16.9)$ & $42(18.8)$ & $14(13.2)$ & $13(17.1)$ & 0.666 \\
\hline Cardiovascular disease & $16(4.4)$ & $7(3.1)$ & $1(0.9)$ & $3(3.9)$ & 0.376 \\
\hline Chronic obstructive pulmonary disease & $7(1.9)$ & $5(2.2)$ & $0(0.0)$ & $0(0.0)$ & 0.276 \\
\hline Asthma & $4(1.1)$ & $3(1.3)$ & $1(0.9)$ & $1(1.3)$ & 0.988 \\
\hline Renal impairment & $31(8.6)$ & $20(8.9)$ & $7(6.6)$ & $8(10.5)$ & 0.819 \\
\hline Cirrhosis & $3(0.8)$ & $2(0.9)$ & $2(1.9)$ & $1(1.3)$ & 0.803 \\
\hline Neoplasm & $2(0.6)$ & $0(0.0)$ & $0(0.0)$ & $0(0.0)$ & 0.521 \\
\hline Trimester of pregnancy, n (\%) & & & & & 0.005 \\
\hline First (0-13 weeks) & $87(24.1)$ & $46(20.5)$ & $17(16.0)$ & $11(14.5)$ & \\
\hline Second (14-26 weeks) & $167(46.3)$ & $81(36.2)$ & $44(41.5)$ & $40(52.6)$ & \\
\hline Third (27-42 weeks) & $106(29.4)$ & $97(43.3)$ & $45(42.5)$ & $25(32.9)$ & \\
\hline Gestational age at admission (weeks), median (range) & $21(2-41)$ & $25(4-40)$ & $24(7-41)$ & $27(7-38)$ & 0.017 \\
\hline \multicolumn{6}{|l|}{ Time from onset of symptoms to swabbing, n (\%) } \\
\hline $0-2$ days & $263(72.9)$ & $167(74.6)$ & $57(53.8)$ & $42(55.3)$ & 0.001 \\
\hline $3-4$ days & $83(23.0)$ & $48(21.4)$ & $47(44.3)$ & $29(38.2)$ & \\
\hline 5-7 days & $15(4.2)$ & $9(4.0)$ & $2(1.9)$ & $5(6.6)$ & \\
\hline Days from onset of symptoms to swabbing, median (range) & $2(0-7)$ & $2(0-6)$ & $2(0-5)$ & $2(0-6)$ & 0.001 \\
\hline
\end{tabular}

Abbreviation: NC not calculated

aDiabetes, neuromuscular disease, and rheumatic disease are not listed because of low numbers

Table 4 Adjusted estimates of risk factors for influenza in pregnant admissions overall and by subtype/lineage

\begin{tabular}{|c|c|c|c|c|c|}
\hline \multirow[b]{3}{*}{ Characteristic } & \multicolumn{5}{|c|}{ Adjusted odds ratio $(95 \% \mathrm{Cl})^{a}$} \\
\hline & Any influenza & $\mathrm{A}(\mathrm{H} 1 \mathrm{N1}) \mathrm{pdm09}$ & $\mathrm{A}(\mathrm{H} 3 \mathrm{~N} 2)$ & B/Yamagata & B/Victoria \\
\hline & $N=825$ & $N=361$ & $N=224$ & $N=106$ & $N=76$ \\
\hline Age (in years) ${ }^{b}$ & $1.02(1.00-1.04)$ & $1.03(1.01-1.06)$ & $1.00(0.97-1.03)$ & $1.09(1.04-1.13)$ & $0.96(0.91-1.00)$ \\
\hline \multicolumn{6}{|l|}{ Trimester } \\
\hline First (0-13 weeks) & 1 & 1 & 1 & 1 & 1 \\
\hline Second (14-26 weeks) & $1.19(0.92-1.53)$ & $1.17(0.82-1.66)$ & $0.89(0.58-1.35)$ & $1.34(0.75-2.51)$ & $2.28(1.10-4.74)$ \\
\hline Third (27-42 weeks) & $1.12(0.86-1.46)$ & $0.82(0.56-1.19)$ & $1.23(0.82-1.87)$ & $1.57(0.86-2.88)$ & $1.58(0.72-3.44)$ \\
\hline \multicolumn{6}{|l|}{ Underlying conditions } \\
\hline No & 1 & 1 & 1 & 1 & 1 \\
\hline Yes & $1.56(1.16-2.08)$ & $1.78(1.19-2.67)$ & $1.91(1.25-2.93)$ & $1.24(0.66-2.34)$ & $2.01(0.39-3.15)$ \\
\hline
\end{tabular}

${ }^{a}$ Adjusted for age, trimester, comorbidity, hospital admission in the previous 12 months, time to swab, and season-week

${ }^{\mathrm{b} C o m p a r i s o n}$ group was influenza-negative pregnant women 
Rates of influenza vaccination and antiviral use before admission were $\leq 1 \%$ and did not differ between influenza-positive and -negative pregnant admissions (Table 2). Smoking habits and socioeconomic class also did not differ between pregnant admissions positive or negative for influenza.

The probability of laboratory-confirmed influenza decreased with the time between symptom onset and swabbing (Table 2). The probability was lowest in pregnant admissions with samples taken 5-7 days after the onset of symptoms $(\mathrm{OR}=0.36$ [95\% CI, 0.24-0.53]; $p=0.001)$. The adjusted probability of a positive result decreased $13 \%$ (95\% CI, 7-18\%) for each day between onset of symptoms and swabbing ( $\mathrm{aOR}=0.87$ [95\% CI, 0.82-0.93]). Time to swabbing differed significantly between subtypes/lineages, although the median was 2 days in all cases (Table 3 ).

\section{Clinical manifestations of influenza in pregnant admissions and pregnancy outcomes}

Fever $(p<0.001)$, cough $(p<0.001)$, and myalgia ( $p$ $<0.001)$ were reported as presenting complaints more often in influenza-positive than influenza-negative pregnant admissions (Table 5). Overall, fever, reported by $97.1 \%$, was the most common presenting complaint in pregnant admissions positive for influenza. The aOR for influenza-positive vs. influenza-negative pregnant admissions was 6.34 (95\% CI, 4.01-10.03) for fever and 2.76 (95\% CI, 2.13-3.43) for cough (Table 6). Cough was a common presenting complaint in pregnant admissions infected with $\mathrm{B} /$ Victoria lineage $(86.8 \%)$ and $\mathrm{A}(\mathrm{H} 1 \mathrm{~N} 1) \mathrm{pdm} 09$ (82.0\%) but less common for those infected with $\mathrm{A}(\mathrm{H} 3 \mathrm{~N} 2)(69.2 \%)$ or B/Yamagata lineage (72.6\%) $(p<0.001)$ (Table 7). Proportions of pregnant admissions reporting all other symptoms (headache, malaise, myalgia, sore throat, and dyspnea) also differed significantly by subtype/lineage. For example, dyspnea was a major presenting complaint in $18.0 \%$ of admissions with $\mathrm{A}(\mathrm{H} 1 \mathrm{~N} 1)$ pdm09 but in less than $5 \%$ of admissions with $\mathrm{A}(\mathrm{H} 3 \mathrm{~N} 2)$ or $\mathrm{B} /$ Yamagata-lineage and in 6.6of admissions with $\mathrm{B} /$ Victoria-lineage.

Hospital admission occurred sooner after the onset of symptoms in influenza-positive than influenza-negative pregnant admissions $(p<0.001)$ (Table 5$)$. This was particularly the case for pregnant admissions positive for influenza $\mathrm{A}(\mathrm{H} 1 \mathrm{~N} 1) \mathrm{pdm} 09$ and influenza $\mathrm{A}(\mathrm{H} 3 \mathrm{~N} 2)$, where more than half went to the hospital on the first day (Table 7). In contrast, more than half of pregnant admissions positive for influenza $\mathrm{B}$ went to the hospital by the second day. As a result, the time to symptom onset differed significantly by strain $(p<0.001)$.

The overall length of hospital stay was not significantly longer for pregnant admissions positive for influenza than those negative for influenza (Table 5); however, pregnant women hospitalized for $>4$ days had a higher probability of laboratory-confirmed influenza than those hospitalized for $\leq 4$ days $(\mathrm{OR}=1.62$ [95\% CI, 1.21-2.16]; $p=0.001$; data not shown). The median hospital stay also differed by subtype/lineage (Table 7) and was longer for pregnant women infected with $\mathrm{B} /$ Yamagata lineage (6.4 days) than for those infected with influenza B/ Victoria lineage (4.9 days; $p=0.025$ [data not shown]) or $\mathrm{A}(\mathrm{H} 1 \mathrm{N1}$ )pdm09 (5.4 days; $p=0.074$ [data not shown]) but did not differ for those infected with $\mathrm{A}(\mathrm{H} 3 \mathrm{~N} 2)$ (5.9 days; $p>0.05$ [data not shown]).

At discharge, the most common diagnosis was other respiratory infections $(n=923 ; 52.8 \%)$ followed by influenza ( $n$ $=725 ; 41.5 \%$ ) (Table 5). Pneumonia was the main discharge diagnosis in 22 cases $(0.1 \%)$ and did not differ between influenza-positive and influenza-negative pregnant women.

Only one influenza-positive pregnant admission and only two influenza-negative pregnant admissions were hospitalized in an intensive care unit (Table 5). No deaths were reported.

\section{Pregnancy outcomes}

Pregnancy outcomes recorded during the hospital stay included 177 live births, 53 abortions (pregnancy stopped before 20 weeks), and 23 stillbirths (Table 5). No perinatal deaths were reported (data not shown).

Abortion was more frequent in influenza-negative than influenza-positive pregnant admissions ( $4.2 \%$ vs. $1.7 \% ; p=0.003)$, although the frequency did not significantly differ by subtype/lineage (Table 7). Frequencies of other pregnancy outcomes did not differ between strains, but predicted probabilities were higher for stillbirth in women infected with B/Yamagata, for cesarean delivery in women infected with $\mathrm{A}(\mathrm{H} 3 \mathrm{~N} 2)$, and for preterm delivery and low birth weight in women infected with B/Victoria (Table 8 and Fig. 2).

Age had a noticeable impact on pregnancy outcomes in influenza-positive admissions. The probabilities of abortion and stillbirth increased with the mother's age, whereas the probability of live birth decreased with the mother's age (Fig. 2). Probabilities of preterm delivery, caesarean delivery, and low birth weight were highest in the youngest mothers, although a second smaller increase in probability occurred in women $35-40$ years of age.

\section{Discussion}

In 2012, the World Health Organization identified pregnant women and newborns as priority risk groups for seasonal influenza [8]. However, the full burden of influenza in pregnant women and their infants is poorly understood due to differences in the design and conduct of epidemiological studies, and the small numbers of pregnant women included [21-23]. The present study describes new epidemiological data of influenza infection among a large cohort of pregnant women, and the impact of influenza on clinical outcomes in these women 
Table 5 Clinical manifestations and outcomes in pregnant admissions by influenza infection status

\begin{tabular}{|c|c|c|c|c|}
\hline \multirow[b]{2}{*}{ Clinical manifestation/outcome } & \multirow{2}{*}{$\begin{array}{l}\text { Influenza positive } \\
\mathrm{N}=825\end{array}$} & \multirow{2}{*}{$\begin{array}{l}\text { Influenza negative } \\
\mathrm{N}=923\end{array}$} & \multirow{2}{*}{$\begin{array}{l}\text { Odds ratio } \\
(95 \% \mathrm{Cl})^{a}\end{array}$} & \multirow[b]{2}{*}{$P$-value } \\
\hline & & & & \\
\hline \multicolumn{5}{|l|}{ Signs/symptoms, n (\%) } \\
\hline Fever & $801(97.1)$ & $781(84.6)$ & $6.07(3.89-9.46)$ & $<0.001$ \\
\hline Headache & $445(53.9)$ & $489(53.0)$ & $1.04(0.86-1.25)$ & 0.688 \\
\hline Malaise & $497(60.2)$ & $550(59.6)$ & $1.03(0.85-1.24)$ & 0.781 \\
\hline Myalgia & $354(42.9)$ & $244(26.4)$ & $2.09(1.71-2.56)$ & $<0.001$ \\
\hline Cough & $630(76.4)$ & $511(55.4)$ & $2.60(2.12-3.20)$ & $<0.001$ \\
\hline Sore throat & $546(66.2)$ & $689(74.6)$ & $0.66(0.54-0.82)$ & $<0.001$ \\
\hline Dyspnea & $86(10.4)$ & $75(8.1)$ & $1.32(0.95-1.82)$ & 0.098 \\
\hline \multicolumn{5}{|l|}{ Time from onset of symptoms to admission, $\mathrm{n}(\%)$} \\
\hline 1 day & $392(47.5)$ & $384(41.6)$ & 1 & \\
\hline 2 days & $209(25.3)$ & $194(21.0)$ & $1.06(0.83-1.34)$ & 0.661 \\
\hline 3 days & $138(16.7)$ & $158(17.1)$ & $0.86(0.65-1.12)$ & 0.254 \\
\hline$\geq 4$ days & $86(10.4)$ & $187(20.3)$ & $0.45(0.34-0.60)$ & $<0.001$ \\
\hline Time from onset of symptoms to admission, median (range) & $2(0-6)$ & $2(0-7)$ & $0.85(0.80-0.91)$ & $<0.001$ \\
\hline \multicolumn{5}{|l|}{ Length of hospital stay, n (\%) ${ }^{b}$} \\
\hline $0-4$ days & $254(30.8)$ & $342(37.1)$ & 1 & \\
\hline 5 days & $155(18.8)$ & $128(13.9)$ & $1.63(1.23-2.17)$ & $<0.001$ \\
\hline $6-7$ days & $261(31.6)$ & $259(28.1)$ & $1.36(1.07-1.72)$ & $<0.001$ \\
\hline Median length of hospital stay (range) & $6(0-35)$ & $5(0-31)$ & $1.00(0.98-1.04)$ & 0.627 \\
\hline Intensive care unit admission, $\mathrm{n}(\%)$ & $1(0.1)$ & $2(0.2)$ & $0.56(0.05-6.17)$ & 0.635 \\
\hline \multicolumn{5}{|l|}{ Pregnancy outcome, n (\%) } \\
\hline Aborted (< 20 weeks) & $14(1.7)$ & $39(4.2)$ & $0.39(0.21-0.73)$ & 0.003 \\
\hline Stillborn ( $\geq 20$ weeks) & $12(1.5)$ & $11(1.2)$ & $1.22(0.54-2.79)$ & 0.631 \\
\hline Live delivery during the current admission, $\mathrm{n}(\%)$ & $78(9.5)$ & $99(10.7)$ & $0.87(0.64-1.19)$ & 0.379 \\
\hline Preterm $(<37 \text { weeks })^{c}$ & $17(21.8)$ & $19(19.2)$ & $1.17(0.56-2.45)$ & 0.669 \\
\hline Cesarean $\neq$ & $14(17.9)$ & $16(16.2)$ & $1.13(0.52-2.50)$ & 0.753 \\
\hline Low birth weight $(<2500 \mathrm{~g})^{c}$ & $3(3.8)$ & $12(12.1)$ & $0.29(0.08-1.07)$ & 0.062 \\
\hline \multicolumn{5}{|l|}{ Discharge diagnosis, n (\%) } \\
\hline Influenza & $617(74.8)$ & $108(11.7)$ & $23.34(18.07-30.13)$ & $<0.001$ \\
\hline Pneumonia & $9(1.1)$ & $13(1.4)$ & $0.77(0.33-1.82)$ & 0.553 \\
\hline Respiratory disease & $187(22.7)$ & $736(79.7)$ & $0.74(0.06-0.09)$ & $<0.001$ \\
\hline Other & $12(1.5)$ & $66(7.2)$ & $0.19(0.10-0.36)$ & $<0.001$ \\
\hline
\end{tabular}

${ }^{\mathrm{a}}$ Estimated by exact logistic regression

broportions are relative to deliveries during the current admission

$\mathrm{N}=825$ for influenza positive, $\mathrm{N}=922$ for influenza negative

and their infants. Using a prospective, active-surveillance study design as part of the GIHSN's hospital-based surveillance [16], we collected data from more than 1700 pregnant women (825 with confirmed influenza) admitted to a hospital specializing in acute respiratory infections.

We restricted the analysis to women aged $15-44$ years. A standard age range (often ages 16-49) is usually [24], but not always [25], chosen to define women of childbearing age. This age-range includes women who are less likely to be pregnant $[24,26]$, as was the case in our investigation the number of pregnant women aged 45-50 was exceedingly small ( $<1 \%$, data not shown). In addition, the distribution of pregnant women in the lowest (15-19 year) and highest (40-44 year) age groups in our study was similar, and we restricted the childbearing age range $(15$ to $<44)$ according to pregnancy probability in our dataset to ensure consistency and reasonable estimates. 
Table 6 Adjusted estimates of risks for clinical manifestations and outcomes in pregnant admissions overall and by subtype/lineage

\begin{tabular}{|c|c|c|c|c|c|}
\hline \multirow[b]{3}{*}{ Characteristic } & \multicolumn{5}{|c|}{ Adjusted odds ratio $(95 \% \mathrm{Cl})^{a}$} \\
\hline & Any influenza & $\mathrm{A}(\mathrm{H} 1 \mathrm{N1}) \mathrm{pdm09}$ & $\mathrm{A}(\mathrm{H} 3 \mathrm{~N} 2)$ & B/Yamagata & B/Victoria \\
\hline & $N=825$ & $N=361$ & $N=224$ & $N=106$ & $N=76$ \\
\hline \multicolumn{6}{|l|}{ Signs and symptoms } \\
\hline Fever & $6.34(4.01-10.03)$ & $5.81(3.02-11.17)$ & $6.36(2.88-10.65)$ & $11.0(2.65-45.73)$ & $5.56(1.31-23.51)$ \\
\hline Headache & $1.03(0.84-1.25)$ & $1.35(1.02-1.77)$ & $0.84(0.62-1.14)$ & $0.72(0.47-1.09)$ & $1.41(0.83-2.40)$ \\
\hline Malaise & $1.05(0.86-1.29)$ & $1.67(1.26-2.22)$ & $0.72(0.53-0.98)$ & $0.56(0.37-0.85)$ & $1.84(1.01-3.33)$ \\
\hline Myalgia & $1.83(1.48-2.26)$ & $2.62(1.98-3.47)$ & $1.16(0.83-1.62)$ & $1.71(1.11-2.63)$ & $2.12(1.28-3.52)$ \\
\hline Cough & $2.76(2.13-3.43)$ & $4.21(3.04-5.83)$ & $2.03(1.47-2.82)$ & $2.14(1.35-3.38)$ & $4.72(2.35-9.45)$ \\
\hline Sore throat & $0.64(0.51-0.80)$ & $0.53(0.39-0.71)$ & $0.71(0.50-1.00)$ & $0.57(0.36-0.89)$ & $0.78(0.44-1.39)$ \\
\hline Dyspnea & $1.10(0.78-1.54)$ & $2.31(1.54-3.49)$ & $0.37(0.18-0.77)$ & $0.42(0.16-1.08)$ & $0.98(0.37-2.63)$ \\
\hline \multicolumn{6}{|c|}{ Days between symptom onset and admission } \\
\hline Below median & 1 & 1 & 1 & 1 & 1 \\
\hline Median or above & $1.43(0.88-2.32)$ & $2.06(1.12-3.79)$ & $1.29(0.56-2.99)$ & $1.15(0.43-3.13)$ & $0.96(0.26-3.51)$ \\
\hline \multicolumn{6}{|l|}{ Length of stay } \\
\hline Below median & 1 & 1 & 1 & 1 & 1 \\
\hline Median or above & $0.94(0.77-1.14)$ & $1.34(1.02-176)$ & $0.72(0.53-0.98)$ & $0.52(0.34-0.80)$ & $1.08(0.65-1.77)$ \\
\hline \multicolumn{6}{|l|}{ Pregnancy outcome } \\
\hline Abortion & $0.32(0.16-0.64)$ & $0.44(0.18-1.09)$ & $0.30(0.09-1.05)$ & $0.36(0.80-1.67)$ & - \\
\hline Stillbirth & $1.10(0.47-2.59)$ & $0.35(0.07-1.72)$ & $1.14(0.30-4.35)$ & $3(0.87-10.28)$ & $1.34(0.25-7.06)$ \\
\hline Live delivery & $0.74(0.52-1.06)$ & $0.78(0.47-1.29)$ & $0.64(0.37-1.10)$ & $0.90(0.45-1.78)$ & $0.62(0.20-1.94)$ \\
\hline Preterm delivery & $0.89(0.45-1.78)$ & $1.07(0.45-2.56)$ & $0.67(0.22-2.06)$ & $0.42(0.05-3.31)$ & $2.42(0.47-2.38)$ \\
\hline Cesarean delivery & $0.96(0.45-2.06)$ & $0.46(0.12-1.70)$ & $1.22(0.44-3.42)$ & $0.87(0.18-4.07)$ & - \\
\hline Low birth weight & $0.34(0.10-1.10)$ & $0.28(0.03-2.13)$ & $0.42(0.09-2.06)$ & - & $2.85(0.29-1.07)$ \\
\hline
\end{tabular}

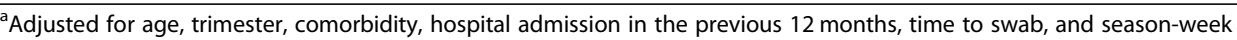

Influenza infection, confirmed by RT-PCR, accounted for nearly half of the admissions over the four influenza seasons. The risk of influenza infection was higher in pregnant than non-pregnant women $(\mathrm{OR}=2.87 \quad[95 \% \mathrm{CI}, 2.10-$ 3.92]), irrespective of subtype/lineage and trimester. This agrees with a larger multi-country study by the GIHSN during the 2012/2013 influenza season, which found an aOR of 3.84 (95\% CI, 2.48-5.94) for influenza-related hospitalization in pregnant vs. non-pregnant women [16]. It also agrees with a meta-analysis of influenza $\mathrm{A}$ infection, which found a combined OR of 2.44 (95\% CI 1.22-4.87) for influenza-related hospitalization in pregnant vs. non-pregnant women, although most of the included studies were during the $2009 \mathrm{~A}(\mathrm{H} 1 \mathrm{~N} 1)$ pandemic season [4].

Underlying conditions, especially anemia, obesity, and asthma, increase the risk of influenza-related hospitalization in pregnant women $[27,28]$. Although we confirmed this in the present study, we were unable to detect significant differences for individual conditions, probably because of insufficient numbers. The present study also confirmed that the risk of hospitalization with influenza does not differ by trimester or influenza subtype, as described by others [29].
Influenza-positive pregnant admissions were hospitalized sooner after the onset of symptoms and stayed slightly longer in the hospital than influenza-negative pregnant admissions. Pregnant admissions positive for influenza also more frequently complained of cough, myalgia, and especially fever than those who were negative for influenza. This suggests that influenza causes more severe illness in pregnant women than other kinds of acute respiratory infection.

Influenza viruses varied substantially between seasons, although all subtypes and lineages resulted in hospitalization. In addition, demographics, clinical manifestations, and rates of stillbirth differed slightly between subtypes/lineages. For example, the risk of influenza infection increased slightly with the mother's age. Also, admissions with influenza $\mathrm{A}(\mathrm{H} 1 \mathrm{~N} 1)$ pdm09 or B/Victoria lineage occurred mostly in the first or second trimester, whereas admissions with influenza $\mathrm{A}(\mathrm{H} 3 \mathrm{~N} 2)$ or $\mathrm{B} /$ Yamagata lineage occurred mostly in the second or third trimester. Although influenza $\mathrm{B}$ has been reported to be more frequent in the second trimester than influenza A [29], these results suggest that the two B lineages cannot be considered equivalent. 
Table 7 Clinical manifestations and outcomes in pregnant admissions by influenza subtype/lineage

\begin{tabular}{|c|c|c|c|c|c|}
\hline & A(H1N1)pdm09 & $\mathrm{A}(\mathrm{H} 3 \mathrm{~N} 2)$ & B/Yamagata & B/Nictoria & \\
\hline Manifestation/outcome & $N=361$ & $N=224$ & $N=106$ & $N=76$ & $P$-value \\
\hline \multicolumn{6}{|l|}{ Signs/symptoms, n (\%) } \\
\hline Fever & $350(97.0)$ & $217(96.9)$ & $104(98.1)$ & $74(97.4)$ & 0.924 \\
\hline Headache & $209(57.9)$ & $110(49.1)$ & $48(45.3)$ & $52(68.4)$ & 0.003 \\
\hline Malaise & $240(66.5)$ & $114(50.9)$ & $51(48.1)$ & $60(78.9)$ & $<0.001$ \\
\hline Myalgia & $191(52.9)$ & $73(32.6)$ & 42 (39.6) & $35(46.1)$ & $<0.001$ \\
\hline Cough & $296(82.0)$ & $155(69.2)$ & 77 (72.6) & $66(86.8)$ & $<0.001$ \\
\hline Sore throat & $215(59.6)$ & $160(71.4)$ & $71(67.0)$ & $56(73.7)$ & 0.009 \\
\hline Dyspnea & $65(18.0)$ & $9(4.0)$ & $5(4.7)$ & $5(6.6)$ & $<0.001$ \\
\hline Time from onset of symptoms to admission, n (\%) & & & & & $<0.001$ \\
\hline 1 day & $195(54.0)$ & $115(51.3)$ & $29(27.4)$ & $31(40.8)$ & \\
\hline 2 days & $98(27.1)$ & $58(25.9)$ & $32(30.2)$ & $13(17.1)$ & \\
\hline 3 days & $40(11.1)$ & $31(13.8)$ & $35(33.0)$ & $16(21.1)$ & \\
\hline$\geq 4$ days & $28(7.8)$ & $20(8.9)$ & $10(9.4)$ & $16(21.1)$ & \\
\hline Time from onset of symptoms to admission (days), median (range) & $1(0-6)$ & $1(0-6)$ & $2(0-5)$ & $2(0-5)$ & $<0.001$ \\
\hline Length of hospitalization stay, $\mathrm{n}(\%)^{\mathrm{a}}$ & & & & & $<0.001$ \\
\hline $0-4$ days & $124(34.3)$ & $61(27.2)$ & $22(20.8)$ & $26(34.2)$ & \\
\hline 5 days & $85(23.5)$ & $32(14.3)$ & $14(13.2)$ & $16(21.1)$ & \\
\hline $6-7$ days & $100(27.7)$ & $84(37.5)$ & $39(36.8)$ & $26(34.2)$ & \\
\hline$\geq 8$ days & $52(14.4)$ & $46(20.5)$ & $30(28.3)$ & $8(10.5)$ & \\
\hline Length of hospitalization stay (days), median (range) & $5(0-35)$ & $6(0-14)$ & $6(1-16)$ & $5(0-11)$ & $<0.001$ \\
\hline Admission to an intensive care unit, $\mathrm{n}(\%)$ & $1(0.3)$ & $0(0.0)$ & $0(0.0)$ & $0(0.0)$ & 0.771 \\
\hline \multicolumn{6}{|l|}{ Pregnancy outcome, n (\%) } \\
\hline Abortion ( $<20$ weeks) & $8(2.2)$ & $3(1.3)$ & $2(1.9)$ & $0(0.0)$ & 0.667 \\
\hline Stillbirth ( $\geq 20$ weeks) & $2(0.6)$ & $3(12.5)$ & $4(3.8)$ & $2(2.6)$ & 0.050 \\
\hline Live delivery during the current admission & $31(8.6)$ & $24(10.7)$ & $14(13.2)$ & $4(5.3)$ & 0.261 \\
\hline Preterm ( $<37$ weeks gestational age $)^{b}$ & $9(29.0)$ & $4(16.7)$ & $1(7.1)$ & $2(50.0)$ & 0.177 \\
\hline Cesareant & $3(9.7)$ & $6(25.0)$ & $2(14.3)$ & $0(0.0)$ & 0.391 \\
\hline Low birth weight $(<2500 \mathrm{~g})^{c}$ & $1(3.2)$ & $1(4.2)$ & $0(0.0)$ & $1(25.0)$ & 0.276 \\
\hline
\end{tabular}

${ }^{\mathrm{a}} N=223$ for $\mathrm{A}(\mathrm{H} 3 \mathrm{~N} 2)$ and $N=105$ for $\mathrm{B} /$ Yamagata

${ }^{b}$ Proportions are relative to deliveries

Influenza, especially $\mathrm{A}(\mathrm{H} 1 \mathrm{~N} 1)$, is considered a risk for stillbirth and low birth weight [27, 30-32]. However, we did not find differences in rates of stillbirth, preterm delivery, or caesarean delivery between influenza-positive and -negative pregnant admissions or between subtypes/lineages. In agreement with this, a recent meta-analysis reported a computed pooled OR of 1.24 (95\% CI, 0.96-1.59) for small for gestational age, suggesting that influenza does not affect birth weight [23]. Unexpectedly, however, abortion before 20 weeks was more frequent in influenza-negative than influenza-positive women, suggesting that other respiratory infections pose a higher risk of abortion.
These data confirm that pregnant women are at increased risk from seasonal influenza $\mathrm{A}$ and $\mathrm{B}$ viruses. With more than 1700 pregnant admissions, this study provides important and detailed information about the impact of influenza in pregnant women that can be used to inform and support vaccination policies in this susceptible population. Furthermore, our study provides pregnancy outcome data, which are rarely included in epidemiological studies of influenza in pregnant women, and have not been published before.

However, this study had some limitations. The main analysis was based on comparing hospitalized influenza-positive with hospitalized influenza-negative pregnant women. We were unable to compare pregnant admissions to 
Table 8 Predicted probability of pregnancy outcomes during admission according to influenza infection status

\begin{tabular}{|c|c|c|c|}
\hline Outcome & RT-PCR result & Adjusted predicted probability ${ }^{a}(95 \% \mathrm{Cl})$ & $n$ \\
\hline \multirow[t]{4}{*}{ Abortion (< 20 weeks) } & No influenza & $0.07(0.05,0.09)$ & 39 \\
\hline & $\mathrm{A}(\mathrm{H} 1 \mathrm{~N} 1) p d m 09$ & $0.03(0.01,0.06)$ & 8 \\
\hline & $\mathrm{A}(\mathrm{H} 3 \mathrm{~N} 2)$ & $0.02(0.00,0.05)$ & 3 \\
\hline & B/Yamagata-lineage & $0.03(-0.01,0.06)$ & 2 \\
\hline \multirow[t]{5}{*}{ Stillbirth ( $\geq 20$ weeks) } & No influenza & $0.02(0.01,0.03)$ & 11 \\
\hline & $\mathrm{A}(\mathrm{H} 1 \mathrm{~N} 1) \mathrm{pdm} 09$ & $0.01(0.00,0.02)$ & 2 \\
\hline & $\mathrm{A}(\mathrm{H} 3 \mathrm{~N} 2)$ & $0.02(0.00,0.05)$ & 3 \\
\hline & B/Yamagata-lineage & $0.06(0.00,0.12)$ & 4 \\
\hline & B/Nictoria-lineage & $0.03(-0.01,0.07)$ & 2 \\
\hline \multirow[t]{5}{*}{ Live delivery during admission } & No influenza & $0.11(0.09,0.13)$ & 99 \\
\hline & $\mathrm{A}(\mathrm{H} 1 \mathrm{~N} 1) \mathrm{pdm} 09$ & $0.09(0.06,0.12)$ & 31 \\
\hline & $\mathrm{A}(\mathrm{H} 3 \mathrm{~N} 2)$ & $0.09(0.05,0.12)$ & 24 \\
\hline & B/Yamagata-lineage & $0.11(0.06,0.16)$ & 14 \\
\hline & B/Nictoria-lineage & $0.08(0.01,0.15)$ & 4 \\
\hline \multirow[t]{5}{*}{ Preterm (<37 weeks gestational age) } & No influenza & $0.13(0.07,0.20)$ & 19 \\
\hline & $\mathrm{A}(\mathrm{H} 1 \mathrm{~N} 1) \mathrm{pdm} 09$ & $0.27(0.06,0.48)$ & 9 \\
\hline & $\mathrm{A}(\mathrm{H} 3 \mathrm{~N} 2)$ & $0.19(0.01,0.38)$ & 4 \\
\hline & B/Yamagata-lineage & $0.06(-0.05,0.17)$ & 1 \\
\hline & B/Nictoria-lineage & $0.54(-0.05,1.13)$ & 2 \\
\hline \multirow[t]{4}{*}{ Cesarean delivery } & No influenza & $0.18(0.09,0.26)$ & 16 \\
\hline & $\mathrm{A}(\mathrm{H} 1 \mathrm{~N} 1) \mathrm{pdm} 09$ & $0.09(-0.02,0.21)$ & 3 \\
\hline & $\mathrm{A}(\mathrm{H} 3 \mathrm{~N} 2)$ & $0.29(0.09,0.49)$ & 6 \\
\hline & B/Yamagata-lineage & $0.15(-0.05,0.36)$ & 2 \\
\hline \multirow[t]{4}{*}{ Low birth weight $(<2500 \mathrm{~g})$} & No influenza & $0.14(0.07,0.21)$ & 12 \\
\hline & $\mathrm{A}(\mathrm{H} 1 \mathrm{~N} 1) \mathrm{pdm} 09$ & $0.05(-0.06,0.16)$ & 1 \\
\hline & $\mathrm{A}(\mathrm{H} 3 \mathrm{~N} 2)$ & $0.06(-0.06,0.17)$ & 1 \\
\hline & B/Nictoria-lineage & $0.55(-0.05,1.15)$ & 1 \\
\hline
\end{tabular}

Abbreviation: $R T-P C R$ reverse transcription-polymerase chain reaction

${ }^{a}$ Adjusted by age, smoking habits, chronic underlying conditions, admission in last 12 months, trimester, time to swab and season-week

non-pregnant admissions because of insufficient numbers of non-pregnant women, who are more frequently admitted for influenza-like illness to other hospitals in Moscow. Nonetheless, the unique nature of the CHID\# 1 study site allowed us to recruit a substantial number of pregnant women. CHID\#1 receives the most pregnant admissions from any of the hospitals in the GIHSN network (over 97\% of the total pregnant admissions based on unpublished GIHSN data from the 2015/2016 season). Another limitation was that we could not assess the long-term effects of influenza on pregnant women, or pregnancy outcome beyond the current admission, because data were collected only from women while they were hospitalized, and follow-up evaluations until the end of pregnancy were not within the study protocol. Finally, the study could have been limited by increasing rates of hospitalization for pregnant women following the 2009 pandemic due to increased awareness of the risks. However, this was probably accounted for by recruiting consecutive admissions without previous knowledge of influenza status. Furthermore, influenza positivity rates were similar over the four influenza seasons, suggesting that this was not a problem.

\section{Conclusions}

Our results confirm that pregnant women are at increased risk from influenza infection irrespective of season, circulating viruses, or trimester. This supports recommendations by the World Health Organization [8] and many countries $[33,34]$ that pregnant women be prioritized for seasonal influenza vaccination. Despite these recommendations and evidence that influenza vaccination is considered safe and effective for pregnant 


\section{A}
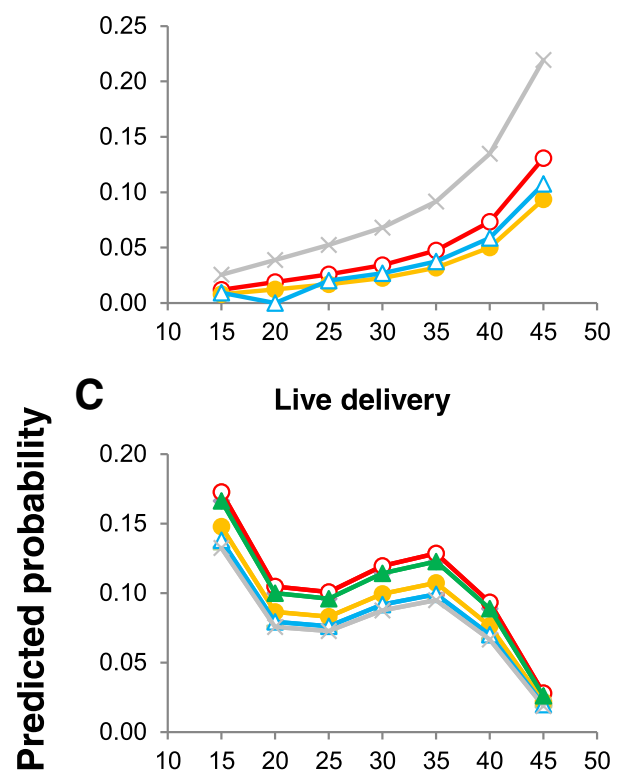

E

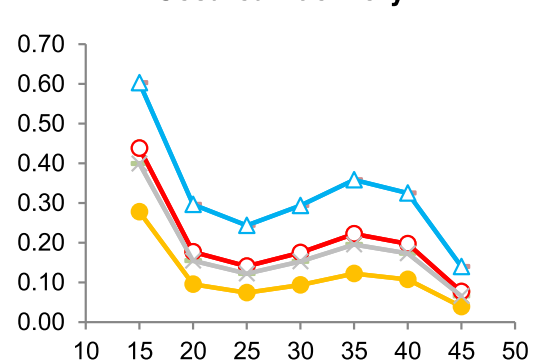

B

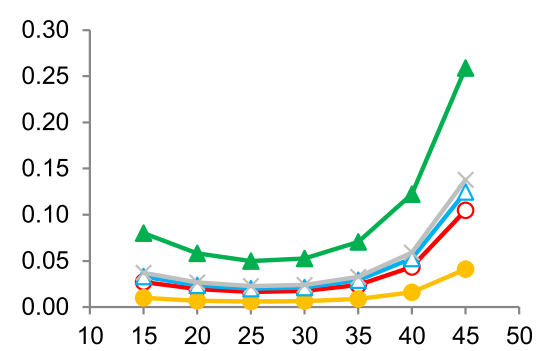

D Preterm delivery

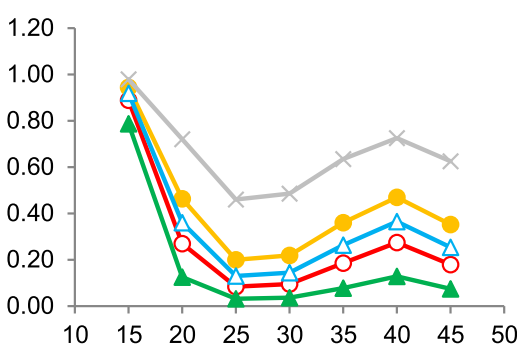

F Low birth weight

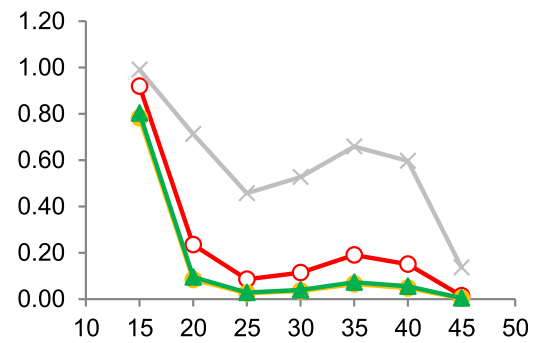

Year
○ $\mathrm{A}(\mathrm{H} 1 \mathrm{~N} 1)$
$\mathrm{A}(\mathrm{H} 3 \mathrm{~N} 2)$
- B/Victoria
$\triangle B /$ Yamagata
* Influenza negative

Fig. 2 Predicted probabilities of birth outcomes according to the mother's age and influenza strain. Predicted probabilities of abortion (a), stillbirth (b), live delivery $(\mathbf{c})$, preterm delivery (d), cesarean delivery (e), and low birth weight (f) in influenza-positive pregnant admissions. Probabilities were adjusted by age, smoking habits, chronic underlying conditions, previous admissions, trimester, time to swab, and season-week

women $[7,10,12,35,36]$, vaccination uptake by pregnant women is generally poor [37], as found in the present study, where $<1 \%$ of pregnant women were vaccinated. Additional efforts are therefore needed to educate healthcare workers, public health officials, and pregnant women about the risks of seasonal influenza and the importance of vaccination.

\section{Additional file}

Additional file 1: Predicted probability of admission with influenza by (a) trimester, (b-e) subtype/lineage, and (f) overall according to age group and presence of underlying conditions. Conditional plots examining interactions between trimester and patient age or presence of underlying conditions for the risk of admission with any influenza or with each subtype/lineage. (PDF $35 \mathrm{~kb}$ )

\section{Abbreviations}

aOR: Adjusted odds ratio; CHID\#1: Federal Budget Institute of Health "Clinical Hospital for Infectious Diseases No. 1"; Cl: Confidence interval; GIHSN: Global Influenza Hospital Surveillance Network; OR: Odds ratio; RT-PCR: Reverse transcription-polymerase chain reaction

\section{Acknowledgements}

Medical writing support was provided by Drs. Phillip Leventhal and Jonathan M. Pitt (4Clinics, France) and paid for by Sanofi Pasteur.

\section{Funding}

The work reported in this manuscript was funded by Sanofi Pasteur. 


\section{Availability of data and materials}

Qualified researchers may request access to patient-level data and related study documents including the clinical study report, study protocol with any amendments, blank case report form, statistical analysis plan, and dataset specifications. Patient level data will be anonymized and study documents will be redacted to protect the privacy of trial participants. Further details on Sanofi's data sharing criteria, eligible studies, and process for requesting access can be found at: https://www.clinicalstudydatarequest.com.

\section{Authors' contributions}

LK1, IK, and LK2 contributed to data acquisition and enrolling participants; ST, $\mathrm{EM} 1, \mathrm{KK}$, and EM2 contributed to laboratory data testing, BG, AM, and ST contributed to data processing, analysis, or interpretation; JP and EB provided overall study oversight and JP wrote the first draft of the manuscript. All authors provided critical review or revisions of the manuscript, approved the final draft, and agree to be accountable for its accuracy and integrity.

\section{Ethics approval and consent to participate}

The study was approved by the "Ethics Committee of Hospital No.1 for Infectious Diseases", CHID\#1, Moscow Health Department, Russian Federation. All participants provided written consent. Written consent was obtained from the parents or legal guardians of participants under the age of 16 years, in line with the GIHSN protocol and local legislation.

\section{Consent for publication}

Not relevant.

\section{Competing interests}

ST, LK1, EM1, IK, KK, EM2, LK2, and EB report grants from Fondation Merieux; grants and non-financial support from Sanofi Pasteur; non-financial support from The Foundation for the Promotion of Health and Biomedical Research of Valencia Region (FISABIO) during the conduct of the study (scientific counselling, discussion on methods, data quality management and analysis, and provision of the study protocol and questionnaires); and grants from the Influenza Division of the US Centers for Disease Control and Prevention outside of the submitted work. The remaining authors have no competing interests to declare.

\section{Publisher's Note}

Springer Nature remains neutral with regard to jurisdictional claims in published maps and institutional affiliations.

\section{Author details}

"Ministry of Health of the Russian Federation, FSBI "N.F. Gamaleya NRCEM", 16, Gamaleya str, Moscow, Russia Moscow 123098, Russian Federation. ${ }^{2}$ Fundación para el Fomento de la Investigación Sanitaria y Biomédica (FISABIO) de la Comunidad Valenciana, Avda Catalunya 21, 46020 Valencia, Spain.

Received: 5 July 2018 Accepted: 15 January 2019

Published online: 15 February 2019

\section{References}

1. Dodds L, McNeil SA, Fell DB, Allen VM, Coombs A, Scott J, et al. Impact of influenza exposure on rates of hospital admissions and physician visits because of respiratory illness among pregnant women. CMAJ. 2007;176(4): 463-8.

2. Mullooly JP, Barker WH, Nolan TF Jr. Risk of acute respiratory disease among pregnant women during influenza a epidemics. Public Health Rep. 1986; 101(2):205-11

3. Neuzil KM, Reed GW, Mitchel EF, Simonsen L, Griffin MR. Impact of influenza on acute cardiopulmonary hospitalizations in pregnant women. Am J Epidemiol. 1998;148(11):1094-102.

4. Mertz D, Geraci J, Winkup J, Gessner BD, Ortiz JR, Loeb M. Pregnancy as a risk factor for severe outcomes from influenza virus infection: a systematic review and meta-analysis of observational studies. Vaccine. 2017:35(4):521-8,

5. Fell DB, Buckeridge DL, Platt RW, Kaufman JS, Basso O, Wilson K. Circulating influenza virus and adverse pregnancy outcomes: a time-series study. Am J Epidemiol. 2016;184(3):163-75.
6. Hewagama S, Walker SP, Stuart RL, Gordon C, Johnson PD, Friedman ND, et al. 2009 H1N1 influenza a and pregnancy outcomes in Victoria, Australia. Clin Infect Dis. 2010;50(5):686-90.

7. Louie JK, Acosta M, Jamieson DJ, Honein MA. Severe 2009 H1N1 influenza in pregnant and postpartum women in California. N Engl J Med. 2010; 362(1):27-35.

8. World Health Organization. Vaccines against influenza WHO position paperNovember 2012. Wkly Epidemiol Rec. 2012;87(47):461-76.

9. Fell DB, Platt RW, Lanes A, Wilson K, Kaufman JS, Basso O, et al. Fetal death and preterm birth associated with maternal influenza vaccination: systematic review. BJOG. 2015;122(1):17-26.

10. Madhi SA, Cutland CL, Kuwanda L, Weinberg A, Hugo A, Jones S, et al. Influenza vaccination of pregnant women and protection of their infants. $N$ Engl J Med. 2014;371(10):918-31.

11. Savitz DA, Fell DB, Ortiz JR, Bhat N. Does influenza vaccination improve pregnancy outcome? Methodological issues and research needs. Vaccine. 2015:33(47):6430-5.

12. Zaman K, Roy E, Arifeen SE, Rahman M, Raqib R, Wilson E, et al. Effectiveness of maternal influenza immunization in mothers and infants. N Engl J Med. 2008;359(15):1555-64.

13. Lambach P, Hombach J, Ortiz JR. A global perspective of maternal influenza immunization. Vaccine. 2015;33(47):6376-9.

14. Mertz D, Kim TH, Johnstone J, Lam PP, Science M, Kuster SP, et al. Populations at risk for severe or complicated influenza illness: systematic review and meta-analysis. BMJ. 2013;347:f5061.

15. Puig-Barbera J, Tormos A, Trushakova S, Sominina A, Pisareva M, Ciblak MA, et al. The global influenza hospital surveillance network (GIHSN): a new platform to describe the epidemiology of severe influenza. Influenza Other Respir Viruses. 2015

16. Puig-Barbera J, Natividad-Sancho A, Launay O, Burtseva E, Ciblak MA, Tormos A, et al. 2012-2013 seasonal influenza vaccine effectiveness against influenza hospitalizations: results from the global influenza hospital surveillance network. PLoS One. 2014;9(6):e100497.

17. Hartert TV, Neuzil KM, Shintani AK, Mitchel EF Jr, Snowden MS, Wood LB, et al. Maternal morbidity and perinatal outcomes among pregnant women with respiratory hospitalizations during influenza season. Am J Obstet Gynecol. 2003;189(6):1705-12.

18. Dolan GP, Myles PR, Brett SJ, Enstone JE, Read RC, Openshaw PJ, et al. The comparative clinical course of pregnant and non-pregnant women hospitalised with influenza a(H1N1)pdm09 infection. PLoS One. 2012;7(8):e41638.

19. Motulsky HCA. Fitting models to biological data using linear and nonlinear regression: a practical guide to curve fitting. New York: Oxford University Press; 2004.

20. Kohler U, Kreuter F. Conditional-effects plots. In: Data analysis using Stata. 3rd ed. College Station, TX: Stata press; 2012. p. 321-4.

21. Katz MA, Gessner BD, Johnson J, Skidmore B, Knight M, Bhat N, et al. Incidence of influenza virus infection among pregnant women: a systematic review. BMC Pregnancy Childbirth. 2017;17(1):155.

22. McMillan M, Porritt K, Kralik D, Costi L, Marshall H. Influenza vaccination during pregnancy: a systematic review of fetal death, spontaneous abortion, and congenital malformation safety outcomes. Vaccine. 2015;33(18):2108-17.

23. Fell DB, Savitz DA, Kramer MS, Gessner BD, Katz MA, Knight M, et al. Maternal influenza and birth outcomes: systematic review of comparative studies. BJOG. 2017;124(1):48-59.

24. Parker J, Branum A, Axelrad D, Cohen J. Adjusting National Health and nutrition examination survey sample weights for women of childbearing age. Vital Health Stat 2 2013(157):1-20.

25. Thompson MG, Kwong JC, Regan AK, Katz MA, Drews SJ, Azziz-Baumgartner $E$, et al. Influenza vaccine effectiveness in preventing influenza-associated hospitalizations during pregnancy: a multi-country retrospective test negative design study, 2010-2016. Clin Infect Dis. 2018.

26. Axelrad DA, Cohen J. Calculating summary statistics for population chemical biomonitoring in women of childbearing age with adjustment for agespecific natality. Environ Res. 2011;111(1):149-55.

27. He J, Liu ZW, Lu YP, Li TY, Liang XJ, Arck PC, et al. A systematic review and meta-analysis of influenza a virus infection during pregnancy associated with an increased risk for stillbirth and low birth weight. Kidney Blood Press Res. 2017:42(2):232-43.

28. Schanzer DL, Langley JM, Tam TW. Influenza-attributed hospitalization rates among pregnant women in Canada 1994-2000. J Obstet Gynaecol Can 2007;29(8):622-9. 
29. Regan AK, Moore HC, Sullivan SG. N DEK, Effler PV. Epidemiology of seasonal influenza infection in pregnant women and its impact on birth outcomes. Epidemiol Infect. 2017;145(14):2930-9.

30. Yates L, Pierce M, Stephens S, Mill AC, Spark P, Kurinczuk JJ, et al. Influenza a/H1N1v in pregnancy: an investigation of the characteristics and management of affected women and the relationship to pregnancy outcomes for mother and infant. Health Technol Assess. 2010;14(34):109-82.

31. Pierce M, Kurinczuk JJ, Spark P, Brocklehurst P, Knight M. Perinatal outcomes after maternal 2009/H1N1 infection: national cohort study. BMJ. 2011;342:d3214.

32. Naresh A, Fisher BM, Hoppe KK, Catov J, Xu J, Hart J, et al. A multicenter cohort study of pregnancy outcomes among women with laboratoryconfirmed H1N1 influenza. J Perinatol. 2013;33(12):939-43.

33. GOV.UK. Annual flu programme. 2018. https://www.gov.uk/government/ collections/annual-flu-programme. Accessed 18 Jun 2018

34. US Advisory Committee on Immunization Practices. Prevention and control of seasonal influenza with vaccines. Recommendations of the advisory committee on immunization practices--United States, 2013-2014. MMWR Recomm Rep. 2013;62(RR-07):1-43.

35. Naleway AL, Smith WJ, Mullooly JP. Delivering influenza vaccine to pregnant women. Epidemiol Rev. 2006;28:47-53.

36. Tapia MD, Sow SO, Tamboura B, Teguete I, Pasetti MF, Kodio M, et al. Maternal immunisation with trivalent inactivated influenza vaccine for prevention of influenza in infants in Mali: a prospective, active-controlled, observer-blind, randomised phase 4 trial. Lancet Infect Dis. 2016;16(9):1026-35.

37. Yuen $\mathrm{CY}$, Tarrant $\mathrm{M}$. Determinants of uptake of influenza vaccination among pregnant women - a systematic review. Vaccine. 2014;32(36):4602-13.

Ready to submit your research? Choose BMC and benefit from:

- fast, convenient online submission

- thorough peer review by experienced researchers in your field

- rapid publication on acceptance

- support for research data, including large and complex data types

- gold Open Access which fosters wider collaboration and increased citations

- maximum visibility for your research: over $100 \mathrm{M}$ website views per year

At $\mathrm{BMC}$, research is always in progress.

Learn more biomedcentral.com/submissions 